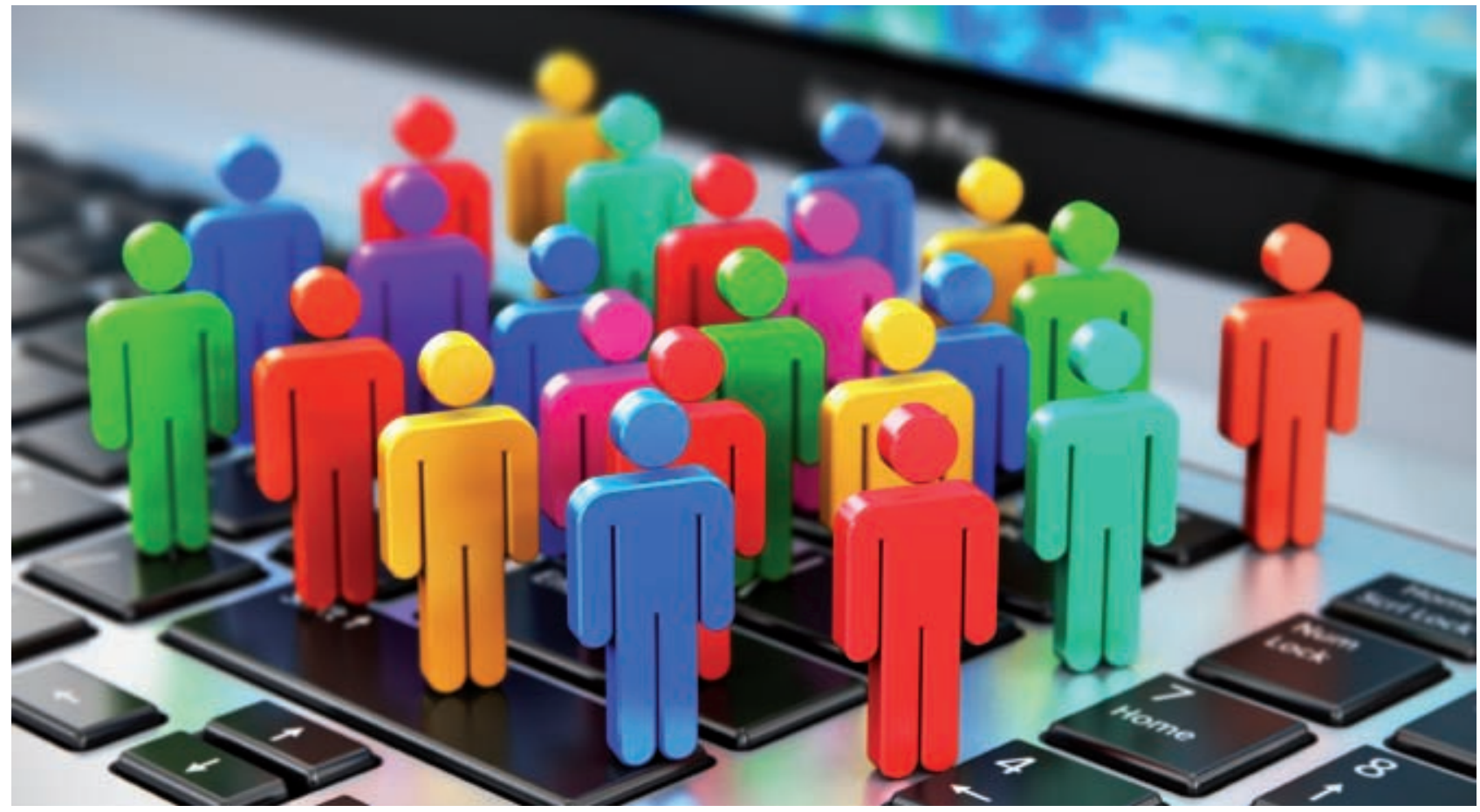

\title{
Pensar y educar \\ en una sociedad de usos y abusos
}

El contexto social actual aporta muchos beneficios a la estabilidad y confort de las personas. Sin embargo, a la hora de educar, los efectos de la sociedad de consumo, de la sociedad tecnológica y de la sociedad

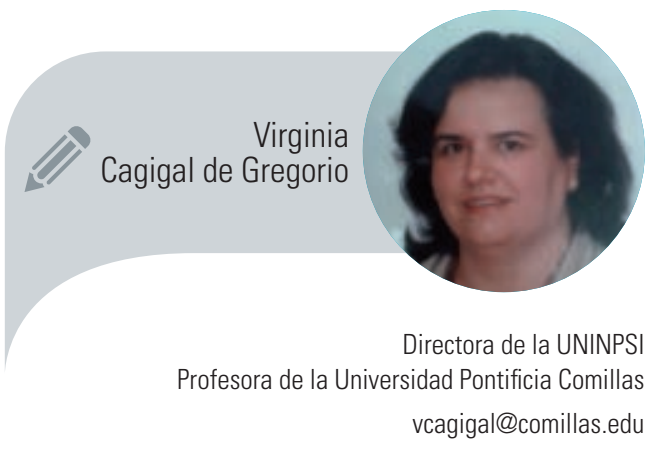
del bienestar pueden destilar creencias y actitudes en los educadores que pongan en riesgo la educación global saludable de niños y adolescentes. A lo largo de estas líneas se reflexiona sobre ello. 


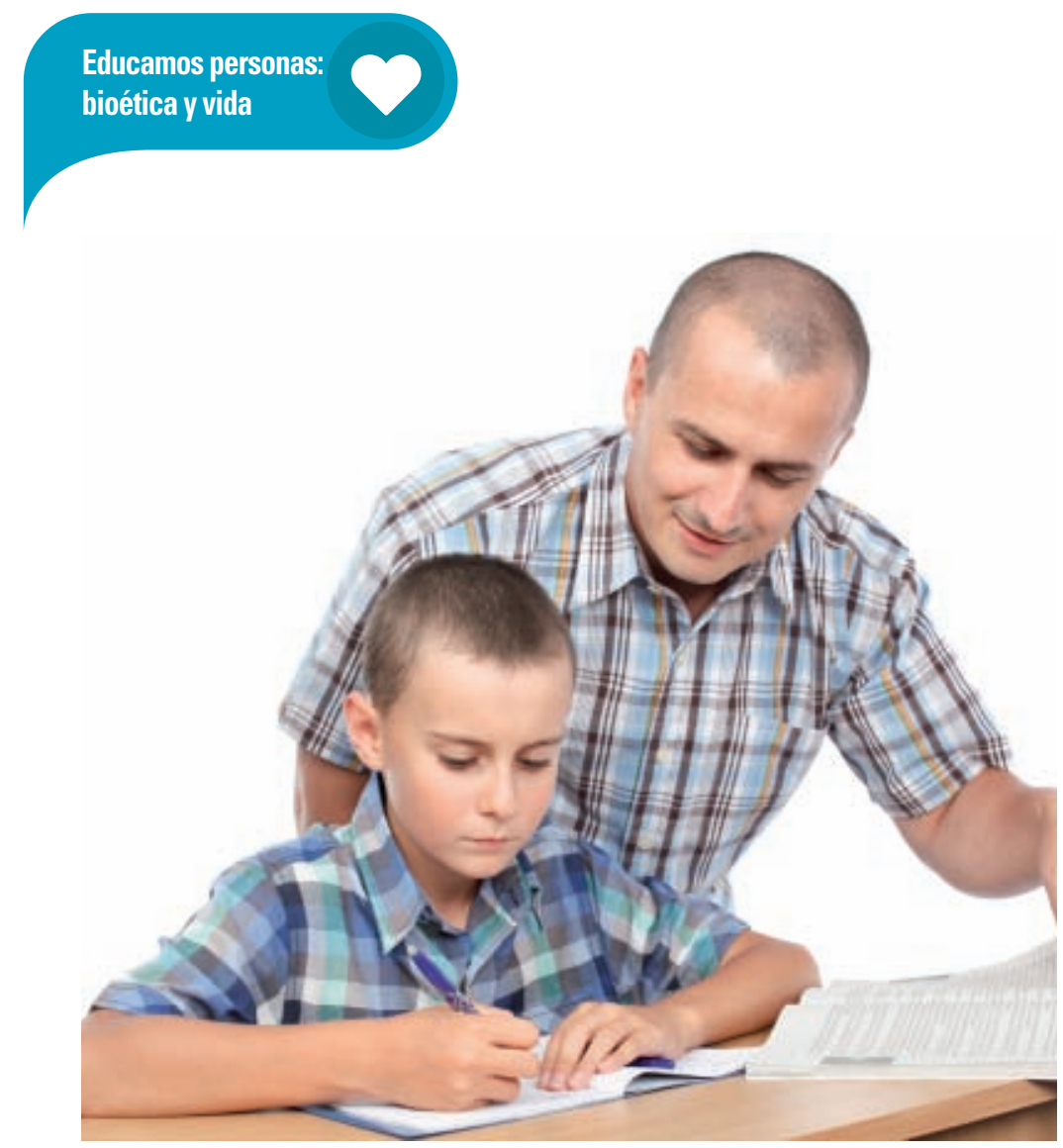

Cada vez más, los padres se preocupan de saber sobre la educación de sus hijos; nunca como ahora se habían vendido libros de educación; se había acudido al centro escolar para hablar con los tutores de los hijos con tanta frecuencia; hay escuelas infantiles que permiten a los padres conectarse vía Internet y saber qué están haciendo o comiendo sus hijos.... y sin embargo, también se observa que es una época de niños especialmente malcriados, caprichosos, así como adolescentes enganchados a lo que pueden para pasar el tiempo o disfrutar sin autocontrol.

Vamos a revisar algunas cuestiones propias de nuestro tiempo sobre las que consideramos que conviene reflexionar de cara a una educación profunda del individuo, que le ayude a aprender a usar lo que tiene, a un consumo responsable, así como a disfrutar en profundidad de y con quienes le rodean. Se pretende no caer en el falaz "cualquier tiempo pasado fue mejor", sino partir de lo que el día a día de esta sociedad del bienestar aporta a las generaciones del momento. Pero reflexionando sobre el posible impacto en la educación de tres grandes características de nuestra sociedad: consumo, tecnologías y bienestar.

\section{Impacto de la sociedad de consumo en la educación}

El entorno social occidental, marcado por una economía de libertad de mercado, permite la elección y la expresión de la propia identidad a través de lo que uno consume y de cómo lo hace. Las posibilidades de elegir se multiplican, permitiendo escoger aquello más acorde con las necesidades o deseos personales.

Al mismo tiempo, el fundamento de la sociedad de consumo es el usar y tirar: la persona adquiere un bien, lo usa y lo tira cuando ya no sirve; incluso se tiende a fabricar para que el objeto dé de sí un número medio de usos, asegurándose de que en no mucho tiempo perecerá y será necesario adquirir uno nuevo. Cabe preguntarse cómo puede afectar este usar y tirar a la construcción de las relaciones humanas.

Cuando la sociedad tiene conciencia de la importancia de reparar, se tiende a arreglar todo lo que sea posible, como hacían las abuelas antaño con los pantalones de sus hijos, tejidos y retejidos, llenos de parches o rodilleras; pero la invitación al consumo lleva al individuo a desechar y sustituir. En las relaciones interpersonales, tanto en la familia como en un contexto social más amplio, este concepto de usar y tirar puede ir calando de forma inconsciente, de modo que con frecuencia se presta poca atención a procesos de perdón y reparación.

En los tiempos en los que se zurcían los calcetines cuando se habían roto, se estaba atento al más mínimo agujerito que tuvieran, para que no se hiciera más grande; en las relaciones familiares actuales, en las que se trabaja poco la reparación, no se está atento a los pequeños "agujeritos", por lo que muchas veces se tarda demasiado en solicitar ayuda, en ponerse a resolver un problema, y para cuando se hace ya el "agujero" es grande y mucho más difícil de arreglar. Por ejemplo, con frecuencia en la terapia llegan parejas que, si se hubieran puesto manos a la obra para abordar la situación unos meses antes, habrían vivido un proceso más rápido y en ciertos casos, con un resultado de mejora de la relación y no de ruptura.

La sociedad de consumo invita a relacionarse con los bienes de la creación desde ese mismo lema de usar y tirar, dejando a 
un lado el concepto de cuidar de ellos. Si se puede usar algo mientras dé de sí y luego se va a sustituir por otro objeto similar, no es necesario cuidarlo, ya sean bienes comunes o particulares. Detrás de conductas de consumo descontrolado y de adicciones en jóvenes, se observa falta de cuidado a uno mismo junto con una necesidad de disfrute compulsivo: carpe diem, vive el momento, disfruta a tope, no hay que estar pendiente de cuidar cómo quedará la persona o el entorno después.

Saber cuidar tiene que ver también con cuidar al otro, salir de uno mismo y caer en la cuenta de sus necesidades y de lo que uno puede ofrecer para aliviarle. Si los niños y los jóvenes no reciben una educación que les capacite para salir de sí mismos y de su propia satisfacción, no aprenden a cuidar al otro, corriendo el riesgo de cosificarlo, de que el otro se convierta en un bien más al que "tengo derecho" porque es para usar (iy tirar!); los datos sobre el creciente incremento de la violencia entre jóvenes novios ponen de relieve en buena medida esta cosificación de la persona y el derecho que uno cree tener de usarla a su antojo, como si se tratara de una propiedad más.

Otro aspecto de la sociedad de consumo a tener en cuenta tiene que ver con que los modelos de disfrute máximo abocan a identificar las relaciones positivas como relaciones de intensidad emocional muy alta. Por ejemplo, se observa cómo hay parejas que cuando decrece el entusiasmo de la fase de enamoramiento, confunden la ausencia de "chiribitas" con que hubieran dejado de quererse. Pero como un árbol de hoja caduca, la pareja (y otras relaciones humanas) va a pasar por etapas frondosas de primavera, fructíferas de verano, de menos expresividad de otoño y etapas de aparente sequía, como el árbol sano en invierno; para el ojo del no entendido, la etapa de invierno se puede confundir con un árbol seco; sin embargo, el buen jardinero sabe que si está seco se aprecia en la raíz, no en la frondosidad imposible en invierno.

En definitiva, hemos querido llamar la atención sobre el potencial efecto nega-

\section{La educación nunca es cosa de prisas, conlleva proceso de aprendizaje, asimilación, procesamiento y consolidación de una forma de hacer, de estar y de ser en el mundo, proceso que no es inmediato}

tivo en el desarrollo de las relaciones interpersonales de la sociedad de consumo; aunque puede resultar más difícil, es necesario enseñar a reparar y trabajar las relaciones para curar heridas, a reconocer al otro por lo que es y no por lo que da de sí, a no sobrevalorar la importancia de las emociones como indicadores de bienestar, así como a identificar las propias necesidades y diferenciarlas de los caprichos que buscan satisfacción compulsiva a través del consumo desaforado o de la adicción.

\section{Impacto de la sociedad de nuevas tecnologías en la educación}

Es indudable que las nuevas tecnologías han aportado a los seres humanos grandes oportunidades de desarrollo y de comunicación; gracias a ellas, es posible diseñar tareas de altísima precisión, que pueden incluso salvar vidas, o tareas muy complejas y que ponen en contacto muy diferentes personas en muy dispares lugares del mundo, o ampliar relaciones y mantenerlas vivas en tiempo real.

Sin embargo, la inmediatez de las nuevas tecnologías puede suponer dificultad en la construcción de la identidad en el sentido de la estabilidad y de la integración (GArcía, Pérez y Escámez, 2009).

En relación con el primer aspecto, el de la estabilidad, el desarrollo de la persona siempre necesita tiempo; la educación nunca es cosa de prisas, conlleva proceso de aprendizaje, asimilación, procesamiento y consolidación de una forma de hacer, de estar y de ser en el mundo, proceso que no es inmediato. 


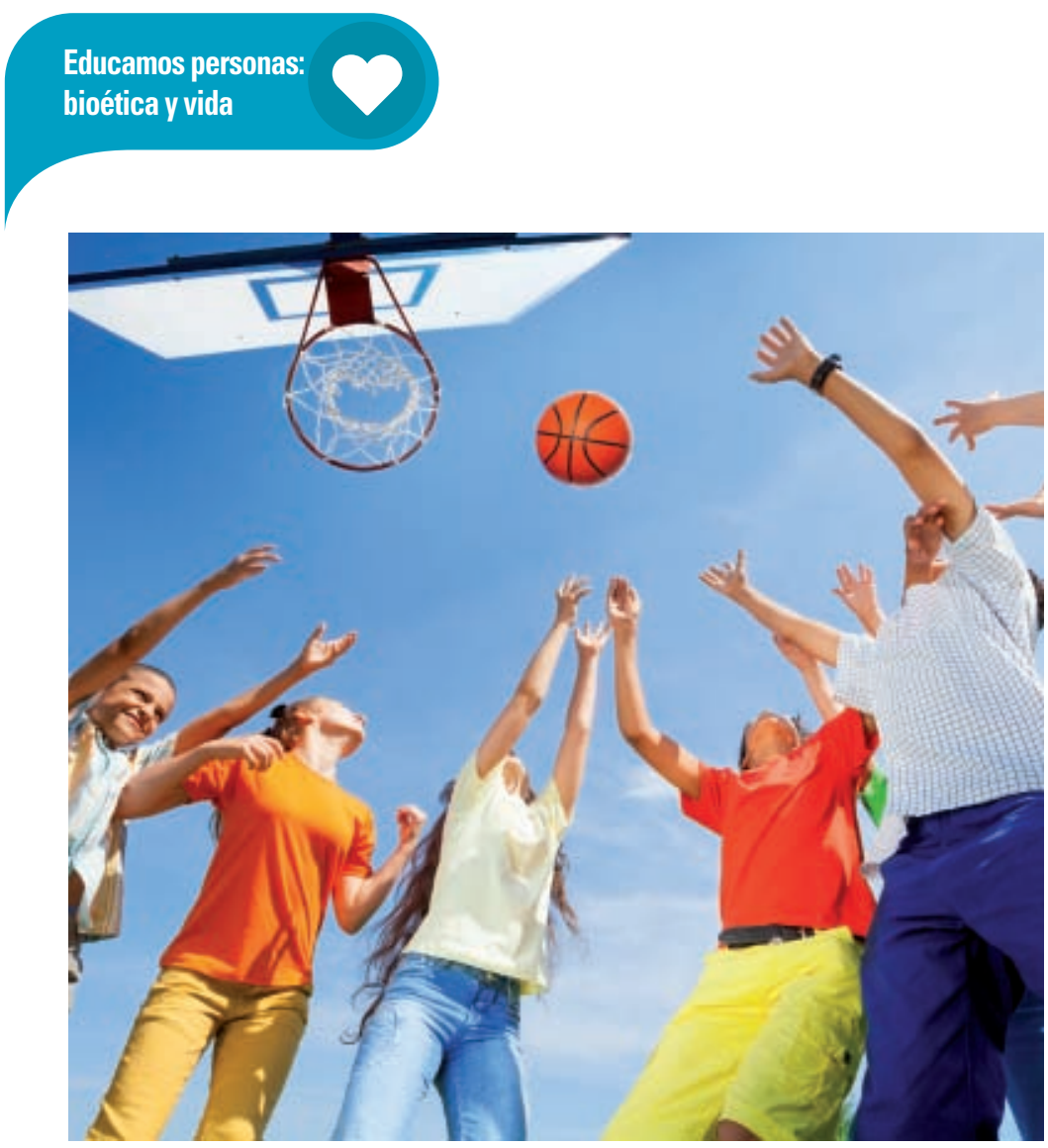

Por otra parte, el gran nivel de inputs de información que llegan a la persona, invita a participar en la sociedad de miles de maneras, haciendo más difícil la integración personal. Actualmente hay voces que ponen de manifiesto el riesgo de dispersión que corren los jóvenes en una sociedad con tantas posibilidades de elección, y al tiempo se identifica un posible bloqueo en su capacidad de tomar decisiones, fruto de esta sobredosis de alternativas.

La rapidez de las nuevas tecnologías "contagia" una forma de mirar la educación en la que falta paciencia y calma a la hora de esperar los frutos de ese proceso educativo, por ejemplo, cuando los padres se quejan de que se lleva un mes trabajando con su hijo a partir de las propuestas del tutor y no está sirviendo porque no ven resultados a corto plazo (lo mismo puede ocurrir a los profesores). La educación tiene mucho más que ver con los tiempos del agricultor que con los tiempos de las nuevas tecnologías, supone sembrar y esperar a que la cosecha crezca, a su tiempo, en su momento, dando buen fruto. El agricultor sabe que no tiene sentido estirar de las plantas para que crezcan más rápido y también que hay que saber recoger la cosecha a tiempo para que no se eche a perder.

Por tanto, no se puede pretender que el niño sea adulto antes de tiempo, depositando en él responsabilidades o compartiendo con él cuestiones de adulto que no está preparado para escuchar o para asimilar. Encontramos algunos ejemplos de este desajuste a la hora de entender qué cabe esperar como frutos de madurez de un niño: una vez un padre llevó a terapia a su hijo porque "es un inmaduro: tiene quince años y no sabe qué quiere ser en la vida, no es capaz de decidir qué quiere estudiar y a qué dedicarse"; a veces, cuando un profesor o un padre describen lo mal que hace las cosas un adolescente, en realidad lo que podemos decir sencillamente es que es un adolescente.

Al tiempo, vivimos en un entorno social que cada vez tiende más a sobreproteger a los niños, frenando su autonomía, lo que hace difícil que los frutos se recojan en el momento en que están maduros. Un ejemplo de esta sobreprotección se observa en cómo muchos padres excusan a sus hijos frenando que el niño adquiera el verdadero aprendizaje de las consecuencias directas de sus actos, tales como afrontar una mala nota si no ha hecho una tarea en lugar de que los padres pongan notitas justificativas al profesor.

Existe una relación estrecha entre el efecto negativo que puede tener la sociedad de consumo en la educación en la familia y la inmediatez tecnológica. Comentábamos más arriba cómo se puede perder de perspectiva la capacidad de cuidar, ya que lo importante es la satisfacción inmediata; pero cuidar para más adelante supone poder demorar las recompensas, frustrarse en el momento para recoger frutos dentro de un tiempo; sin embargo, la sociedad tecnológica insta a conseguir los frutos de forma inmediata, por lo que no hay proceso de frustración y confianza que permitiría mantener el esfuerzo más allá del momento.

\section{Impacto de la sociedad del bienestar en la educación}

A través de la sociedad del bienestar, se ha logrado en los entornos occidentales estándares de vida confortable que cubren muchas necesidades de las personas de forma accesible para casi todos; salud, educación, justicia, son algunos 
derechos a los que una amplia mayoría social tiene acceso (no nos detenemos a hablar de las desigualdades sociales en el entorno más inmediato, no porque obviemos esta realidad, sino porque, incluso aunque se sufran, siguen calando aquellos aspectos de ideal social que el entorno plantea como lo deseable para la persona, que son objeto de análisis en este artículo por su impacto en la educación).

Bienestar significa "estar bien", Io que invita a concebir las relaciones como siempre afables, siempre serenas, pasando por encima las dificultades y los desajustes, en un patrón de evitación de conflicto. Los padres que quieren educar bien, necesariamente, tienen conflicto con sus hijos, un conflicto manejable en términos de respeto mutuo y jerárquico, por supuesto, pero conflicto. Es un desajuste importante en la educación confundir que las cosas van bien porque no se discute en casa, ya que se puede estar soslayando aspectos fundamentales a abordar, bajo ese paraguas de que no hay dificultades.

La sociedad del bienestar invita a un deseo de "siempre más y mejor", de considerar sólo los derechos con el riesgo de perder de referencia la importancia de los deberes para la convivencia social. Al aprender a reconocer las necesidades del otro y a dar el justo valor a las propias, el niño va ajustándose a lo que de verdad necesita para estar y sentirse bien en la vida, consolidando una sana serenidad capaz de luchar por lo que merece la pena pero sin dejarse invadir por una avidez innecesaria.

\section{Conclusión: hacia una educación en responsabilidad}

La familia es el principal referente de desarrollo de la identidad. El niño va construyéndose en respuesta a las preguntas "¿quién soy?" y "¿quién quiero ser?". Las primeras respues tas que recibe vienen de afuera, de las figuras de referencia, y progresivamente va introyectando una imagen de sí mismo, de su relación con los demás y de su relación con el mundo, que van conformando esa identidad.
Los padres son los principales referentes en ese desarrollo; los valores que transmiten y su forma de entender el mundo y de entenderse a sí mismos en el mundo son pilares básicos para la consolidación de la estructura fundamental de la personalidad de sus hijos. Los profesores también colaboran en esta tarea de forma muy importante, y no se puede perder de vista que siempre el docente es, ante todo, un educador, referente en el crecimiento para el niño o el adolescente.

La comprensión ética de los adultos de referencia sobre la sociedad, la identidad y la trascendencia de uno mismo van a conformar las actitudes básicas de los hijos y alumnos para estar en el mundo y relacionarse consigo mismos y con los demás. Si el educador toma decisiones basadas en la reflexión previa sobre qué quiere transmitir al niño, cómo es mejor transmitir lo deseado y qué efectos puede tener, las propuestas educativas serán firmes, claras, y ofrecerán al niño una educación con libertad responsable, que sustentará su desarrollo estable como persona •
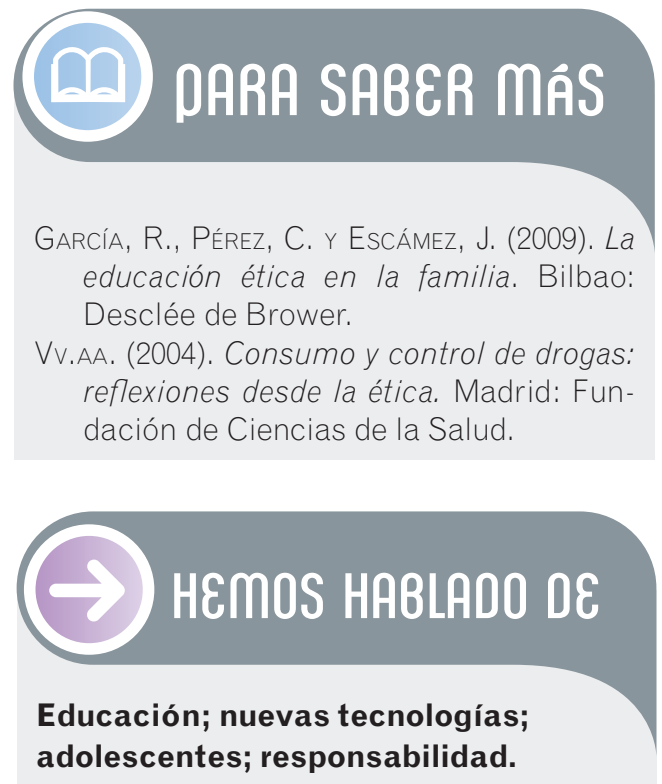

Este artículo fue solicitado por PADRES y MAESTROS en diciembre de 2014, revisado y aceptado en mayo de 2015. 